\title{
Development of Oil Palm Loose Fruit Collecting Machine with Elevated Discharge Mechanism (Mark Iii)
}

\author{
Abd Rahim Shuib, Mohd Ramdhan Khalid, Mohd Azwan Mohd Bakri, \\ Mohd Solah Deraman and Norman Kamarudin \\ (Biological Research Division, Farm Mechanisation Unit, Malaysian Palm Oil Board, \\ Bandar Baru Bangi, 43000 Kajang, Selangor Darul Ehsan, Malaysia)
}

\begin{abstract}
The Loose Fruit Collecting Machine (MK IV) is a device where the loose fruits are collected into a cone shape barrel using a cyclonic vacuum concept. With its cone shape, it creates a cyclone atmosphere once the fruits are inside which could minimise bruise to skin of the fruit. The primary objective of this innovation is to utilise vacuum concept to draw in loose fruits into a container. The machine is maintaining the suction that as in previous model utilising vacuum cyclone concept. The loose fruits are sucked into a cylindrical shape of casing or barrel. As the fruits are circulating the barrel/chamber the 'heavier' fruits will fall to the bottom of the barrel while the lighter materials such as dried leaves will be sucked out of the system. This technology is also capable of separating the collected loose fruits and the debris into two layers in the vacuum chamber hence producing clean loose fruit at the bottom of the fruit barrel. The machine is easy to operate, fast operation and important to state that the operator will no longer having back-pain problem. The additional mechanism that has been improved are, the barrel which now is being functioned as a temporary storage area. The contents in the barrel occasionally say after the machine has visited 10 points collection or palms be emptied into another container that can hold up to $500 \mathrm{~kg}$ of fruits. Once the amount of fruits in the container reaches 500 $\mathrm{kg}$, the operator will lift and unload them into mainline transport system either a waiting trailer, bin or sterilizer cage.
\end{abstract}

The machine is capable of collecting on average of $1500 \mathrm{~kg}$ to $2000 \mathrm{~kg}$ of clean loose fruits in a day. With the proposed design, the machine is also well integrated with mainline transportation system i.e. the sterilizer cage system.

Keywords: Loose fruit, elevated discharge mechanism, suction, cyclone

\section{INTRODUCTION}

Oil palm loose fruits contain maximum oil, which is why they need to be fully collected. Large amounts of loose fruits are scattered due to impact as a result of bunches falling to the ground during the harvesting activity. Thus, loose fruits are currently collected by hand picking or raking (Figure 1). This technique is not only labour demanding, and time-consuming but also is tedious and laborious. On the average, the time taken for the worker to collect loose fruits was about $28 \%$ from total time of harvesting. Furthermore, the worker need to squad and stand up thorough out the day during the collection process. This action contributes to their tiredness hence reflected their productivity.

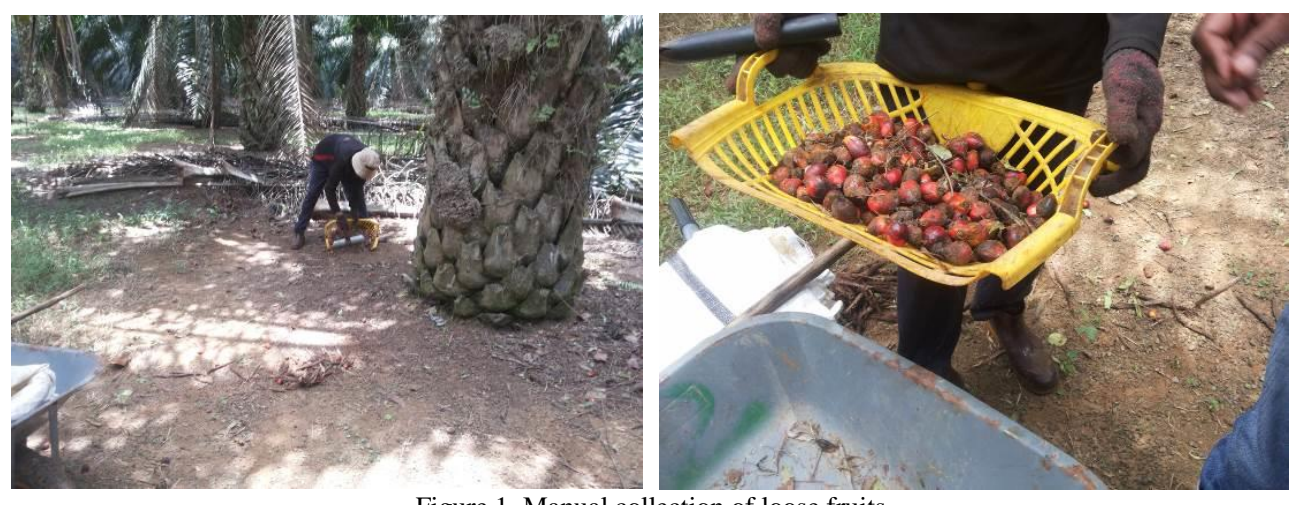

Figure 1. Manual collection of loose fruits

Oil palm fresh fruit bunches (FFB) need to be harvested at the optimum maturity stage to optimise the quality of palm oil. Harvesting involves removing the ripe bunches, collecting and sending them to the mill for oil extraction. The harvesting rounds are organised throughout the year so that the same palm is visited every two weeks during which the workers will harvest any ripe bunch using a chisel on a short pole, or a sickle on a longer pole for taller palms [4].

Loose fruit is referring to the individual fruit that is detached from ripe bunch and its number will indicate the readiness of that particular bunch is ready for harvesting. The numbers can range from only one to ten 
loose fruits detached from the bunch depending on the company policy. These individual loose fruits that were detached from bunches should be collected because it contains high oil. [5] Reported that laboratory tests carried out on fruits coming from outer layer of bunches contributing nearly 50 per cent of the total percentage of oil to bunch. Therefore, if the fruit is not collected coincidently which is the outer layer of the bunch, it can cause a drop-in oil extraction rate (OER) as a big portion of them has gone. [5] says if the loose fruit is not collected and processed, the loss of OER is more significant for FFB of young palm compared with old one. This is because young trees have small bunch size and number of fruits less per bunch. [5] Also reported that the loss of 20 fruits each bunch can reduce OER of $0.92 \%, 0.46 \%$ and $0.37 \%$ for oil palm trees in 1-5 years, 6-15 harvest year and more than 15 years. In the context of oil palm cultivators, if the loose fruits are not collect it will affect their annual income. A simple mathemical model can be used to estimate the losses.

\section{$\mathrm{P} \times \mathrm{Q} \times \mathrm{R} \times \mathrm{S} \times \mathrm{T}$}

Losses $(\mathrm{RM} /$ ha $/$ year $)=$

$1,000,000$

Equation [1]

where;

$\mathrm{P}=$ weight of loose fruit, $(\mathrm{g})$

$\mathrm{Q}=$ number of loose fruit not collected per bunch

$\mathrm{R}=$ no of bunches/palm/year

$\mathrm{S}=$ stand per ha (palm/ha)

$\mathrm{T}=$ Price FFB, (RM/tonne)

To estimate the losses for a particular time, replacing the value of $P=10, Q=10, R=15, S=148$ and $T=500$, hence the losses are RM 111/ha/year.

During harvesting, handling and transportation operations, ripe fruits become easily detachable from the bunch. Study by [6] indicates that by using the harvesting machine, the amount of detached loose fruits produced during harvesting was reduced $45 \%$ compared to manual harvesting as the cut bunches will be conveyed into container carried by machine. With the absence of bunches impact, the amount of loose fruit scattered on the ground is minimise.

Loose fruit, its collection and non-collection, has always been one of the hottest topics talked about in the daily operation of the upstream plantation. Historically, loose fruit was not given much attention. They were deemed insignificant compared to the FFB which is larger in size. Hence the collection of loose fruit was never taken seriously. Many of the fruit was left to rot. However, various studies revealed that oil palm loose fruits contained maximum oil, which is why they need to be fully collected.

\section{Manual Method}

Loose fruits are currently collected by hand picking or raking. This technique is not only labour demanding, and time-consuming but also is tedious and laborious. The workers need to squat and stand up thorough out the day during the collection process. This action contributes to their tiredness. Furthermore, by raking the debris collected can be as high as $60 \%$ by weight [3]. It was estimated that time taken to collect loose fruits is about $30 \%$ of the total fruit handling time. The average productivity of each operator is $200 \mathrm{~kg}$ to $250 \mathrm{~kg}$ of fruits day $^{-1}$ depending on various factors.

\section{Mechanised collection}

A cost-effective loose fruit collection system is still one of the main targets of oil palm industry. Various inventions have been introduced but the objective has not been met due to the various technical limitations and constraints [1].

Among the objectives for mechanising loose fruits collection are:
a) Reduction in labour requirements
b) Reduction in cost of production
c) Increase in productivity per worker
d) Maximum fruits recovery

Various inventions on loose fruit collecting machine have been introduced but the success is rather questionable due to the mix of several technical limitations, constraints as well as economic reason Figure 2. Basically, there are two types of approaches have being tested to assist loose fruit collection activity i.e. mechanical and suction methods.

Previous work on the suction method was suffered from lack of engine horse power where the vacuum created by the engine was not strong enough to avoid choking problem. This choking problem is very serious particularly during wet weather where the fruits are moist. 

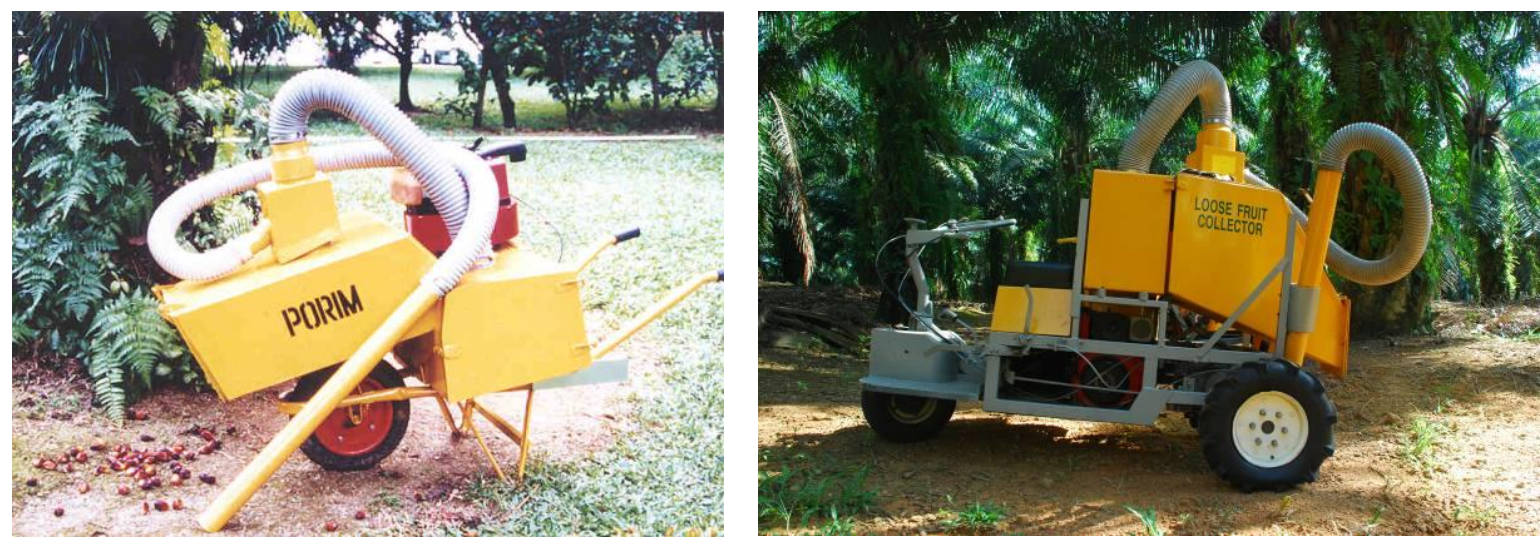

Figure 2 Among the loose fruits collecting machines that were developed by MPOB

To overcome this issue, an upgrade version was then developed by [2] and now utilising vacuum cyclone concept. Constant suction power is the main advantage of a cyclonic vacuum. Idea of vacuum cyclone was originated in 1980s by James Dyson to be used as a vacuum cleaner. Using this concept for collection, the loose fruits are sucked into a cylindrical shape of casing or barrel where a cyclone atmosphere created once the fruits inside hence contribute to minimum bruising to the skin of the fruit. As the fruits are circulating the barrel or chamber the heavy fruits will fall to the bottom of the barrel while the lighter materials such as dried leaves will be sucked from the system. Ability to separate debris also being integrated with the machine hence producing clean loose fruit at the bottom of the fruit barrel.

The machine was capable of collecting of $4.2 \mathrm{~kg}$ $\min ^{-1}$ to $5.1 \mathrm{~kg} \mathrm{~min}^{-1}$ loose fruits with less than $15 \%$ debris. Fruits were not damaged or bruised during the operation. On the average, this machine is capable of collecting 1200 to $1500 \mathrm{~kg}$ of clean loose fruits in a day.

However, from previous field trials, it was noticed that if the fruits occupy more that $50 \%$ of the barrel volume, there is higher tendency of trash is not to be blown out hence affecting its performance. In this new design, the barrel now acts as a temporary storage facility where its contents will occasionally be emptied into another container within the machine chassis and later be discharged directly into trailer, awaiting bin or sterilizer cage. The elimination of these loose fruits bags that need to be line-up along the collection roads can possibly reduce manpower requirement.

\section{METHODOLOGY}

\section{Materials \& Methods}

The machine is maintaining the suction concept (vacuum cyclone) that as in previous model [2]. The loose fruits are sucked into a cylindrical shape of casing or barrel. As the fruits are circulating the barrel/chamber, the 'heavier' fruits will fall to the bottom of the barrel (as it losses the energy) while the lighter materials such as dried leaves will be sucked out of the system Figure 3. This technology is also capable of separating the collected loose fruits and the debris into two layers in the vacuum chamber hence producing clean loose fruits at the bottom of the fruit barrel. The machine is easy, fast to operate.

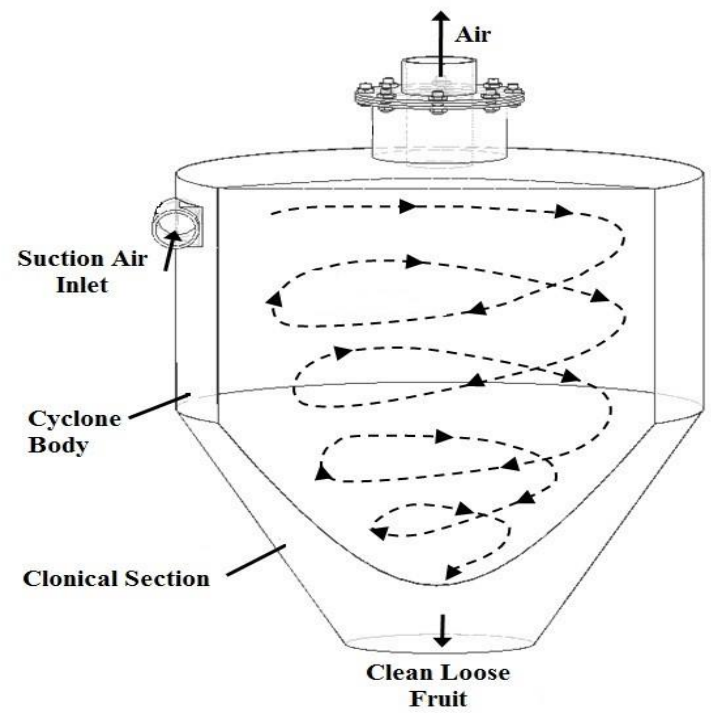

Figure 3 The cyclonic vacuum concept 
The additional mechanism that has been improved are, the barrel, which now functions as a temporary storage area. The contents in the barrel are occasionally emptied into another container that can hold up to $500 \mathrm{~kg}$ of fruits. Once the amount of fruits in the container reaches $500 \mathrm{~kg}$, the operator will lift and unload them into mainline transport system either a waiting trailer, bin or sterilizer cage. Emptying the content is made easy with a hydraulic control lever. The basic components of the machine are shown in Figure 5 and the general specifications are shown in Table 1.

\section{TABLE 1. GENERAL SPECIFICATIONS OF THE MACHINE}

\author{
Dimension (mm) \\ Minimum tractor power \\ Suction Power \\ Suction Hose \\ Fruits container \\ Tyre Size \\ Unladen Weight \\ Elevated discharge height
}

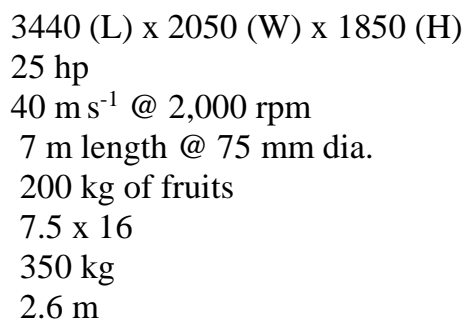

Figures 4 (a) and (b) show the scissors lift fruit bin design having a space to accommodate loose fruit. The fruit bin floor and lower side walls were rigidly built to overcome the impact of the falling loose fruit. The total volume of the fruit bin was $2150 \times 106 \mathrm{~mm}^{3}$ and was designed to accommodate $500 \mathrm{~kg}$ of fresh fruit bunches. The front sidewall was made inclined at $45^{\circ}$ to assist in the movement of the loose fruit to the far rear end as they were being dropped into the bin. While the machine was operating in the plantation, the collected loose fruits were further self-organised by themselves in the fruit bin during the travelling time. The rear bin wall was inclined about 30 degree with respect the floor of the fruit bin in order to provide a wide opening for easy flow and free falling of the loose fruit during the dumping process. The fruit bin was lifted up by the scissors lift to a $2700 \mathrm{~mm}$ height by a single step scissors lift for dumping its contents into the mainline transporters. Machine stability at the maximum raised height of the scissors lift was considered in the design. The two hand levers, located at the left side of the operator, control the lifting and tipping of the fruit bin manually.

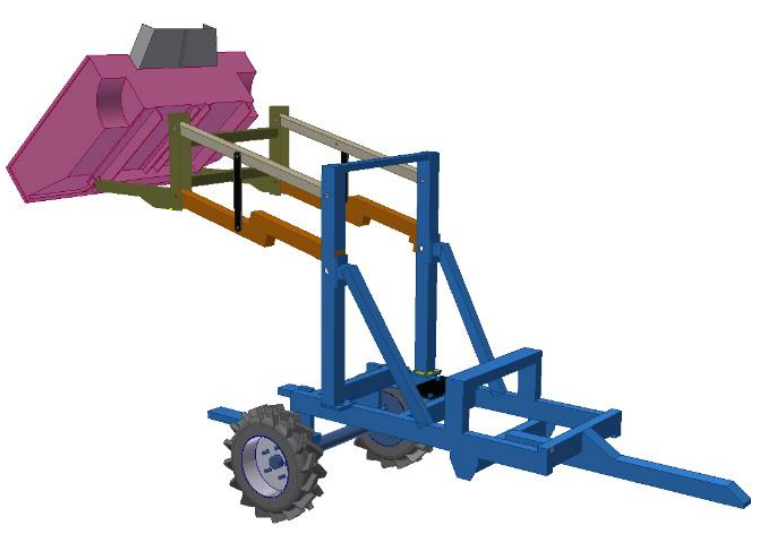

(a)

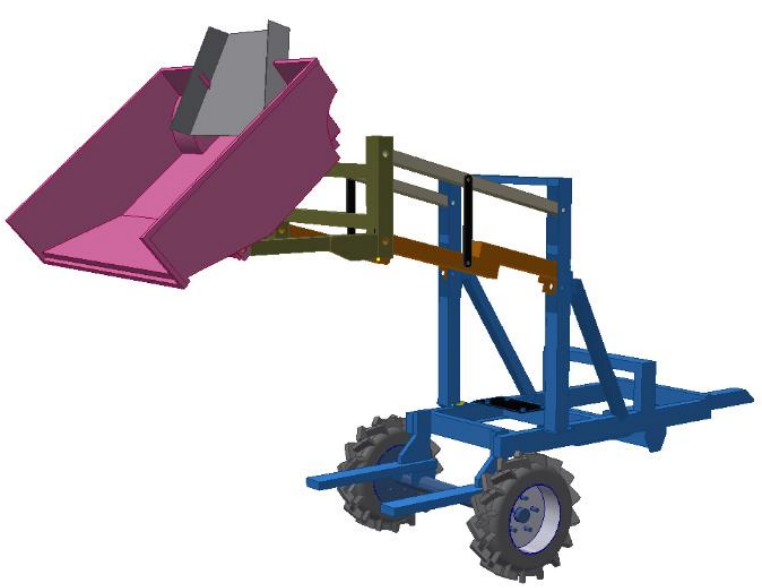

(b)

Figure 4 The conceptual design of the elevated discharge system

\section{Cylinder Pressure for scissors lift Unit}

The cylinder hydraulic pressure for the scissors lift unit was estimated based on the hydraulic pressure to lift up the scissors unit with the loose fresh fruit from the ground to the fruit bin topmost position. The scissors unit mass was $400 \mathrm{~kg}$ and the fresh fruit bunch mass was 500 $\mathrm{kg}$. The hydraulic cylinder with a bore diameter equal to
$7.50 \mathrm{~cm}$ was selected to create cylinder pressure in order to provide such force at the required speed. The cylinder pressure required to lift up the bin with loose fruits was determined by the following equation: 


$$
P=\left(\frac{F}{10 x A}\right)
$$

$$
\text { Equation .... [2] }
$$

where:

$$
\begin{array}{ll}
P & =\text { cylinder pressure, } \mathrm{bar} \\
F & =\text { cylinder piston force }, \mathrm{N} \\
A & =\text { cylinder piston area, } \mathrm{cm}^{2}
\end{array}
$$

The cylinders hydraulic pressure for the scissors lift was estimated based on the hydraulic pressure to lift up the scissors lift and its fruit bin in to its topmost position before tipping the fruit bin contents into the mainline transport truck. The mass of the scissors lift was $400 \mathrm{~kg}$, the mass of the fruit bin was $225 \mathrm{~kg}$, and the mass of the payload of loose fruit was $500 \mathrm{~kg}$. Therefore, the total mass to be lifted by the two hydraulic cylinders of the scissor lift was equal to $1125 \mathrm{~kg}$. The total cylinders pressure required to lift the scissors lift were determined by using equation 2. Using $\mathrm{F}$ equal to11036.25 $\mathrm{N}$ and two cylinders' bore area equal to $45.37 \mathrm{~cm}^{2}$ in the said equation give $\mathrm{P}$ equal to 32.43 bar. Thus, a pressure of 32.43 bar was needed to lift the fruit bin at its full payload to the topmost position.

\section{Lifting and Lowering Scissors Lift}

When the lifting control lever was moved to the lift position, the directional control valve directs the

flowing oil from the hydraulic gear pump to the two scissors lift cylinders. The oil expands the piston shaft out to lift up the scissors lift bars and the fruit bin. When the position control lever was moved to the down position, the directional control valve directs the oil flow to the second port to retract the scissors lift cylinders and lowers the scissors lift with the fruit bin.

\section{Tipping and Lowering the Fruit Bin}

When the tipping control lever was moved to the tipping position, the directional control valve directs the oil flow from the hydraulic gear pump to the fruit bin cylinder. The oil pushes the piston out to lift up the fruit bin from the frontage to tip its contents to the back. When the position control lever was moved to the down position, the directional control valve discharges the oil to the oil tank by the weight of the fruit bin allowing the fruit bin to return back to its normal position.

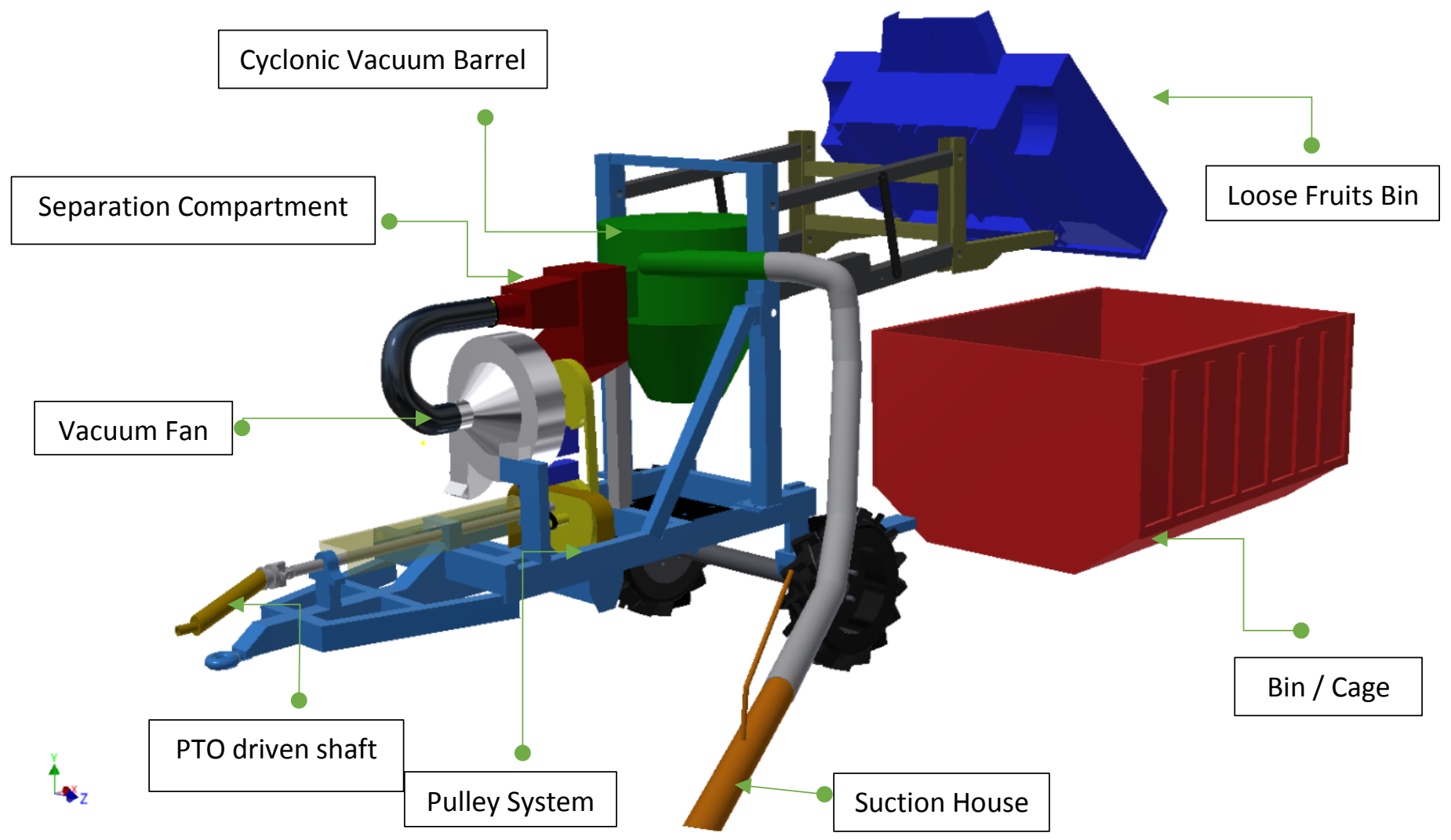

Figure 5 The basic components of the machine 


\section{RESULT AND DISCUSSION}

Figure 6 shows the fully developed loose fruit collecting with high discharge point from the rear view. The high speed of air was created by having a propeller fan rotating at 4,000 rpm. The power to propel the fan shaft is coming from tractor's PTO shaft via cardan shaft. Since the speed of PTO shaft is only $540 \mathrm{rpm}$ a two stage step up pulley was installed to the system. The diameter of fan is
$450 \mathrm{~mm}$ where the fan blades were made aluminium in order to reduce the weight.

A functional test was conducted to ensure the prototype is working as it designed for. The prototype was then sent to a commercial estate for field evaluation. Data on productivity, cost effectiveness, time taken and labour requirement were collected and analysed.

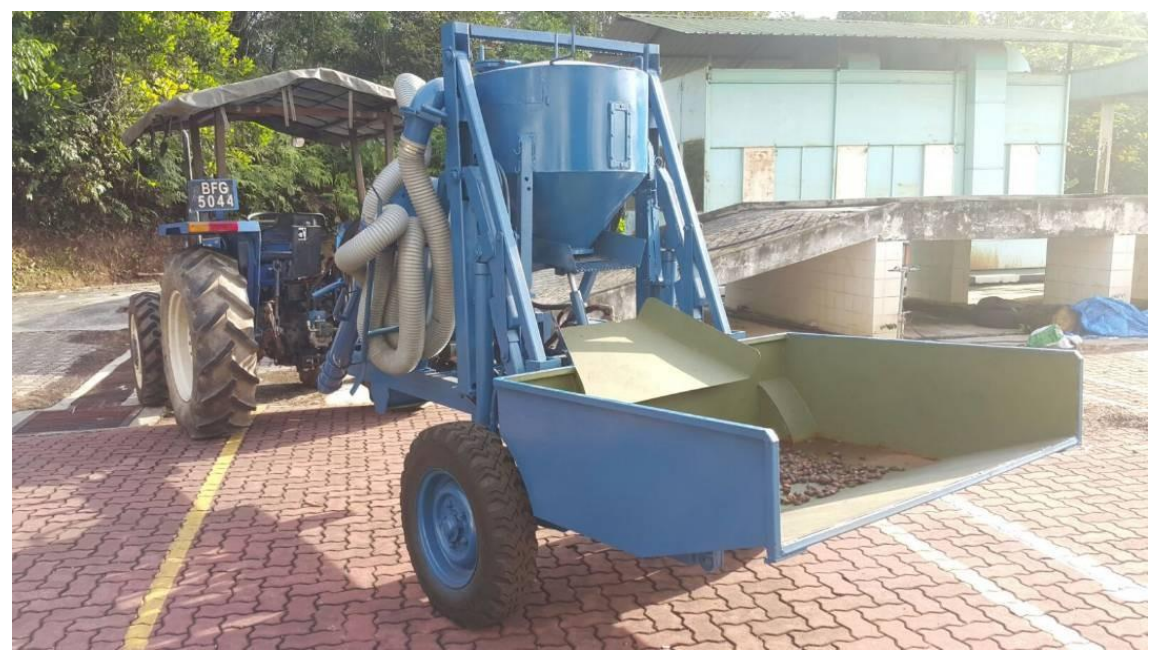

Figure 6 The fully developed loose fruits collecting machine.

\section{Machine System Operation}

Figure 7 summarises the involved operational steps with the machine system. In the system operation the operator steers the machine system forward to the location where the loose fruits has been gathered into a point. Upon reaching the heaped loose fruit, the operator who is sitting on tractor seat activates the PTO shaft in order to propel the fan and when there is sufficient flow of air at the suction hose is strong enough, loose fruits will suck into barrel through hose. The operator then steers the machine to collect next point within the field plot area. Upon completion of the collection trip, the operator drives the machine to the roadside closed to the waiting mainline transporters and operates the respective levers to lift the scissors lift and tip the fruit bin contents into the mainline transporters. Next step the operator lowers the emptied fruit bin to the rest position while driving the machine back to the next field plot for a new collection trip.

A field trial was carried out on a commercial oil palm estate to evaluate the machine's performance. It was found that the suction power is sufficient with an average air velocity of $40 \mathrm{~m} \mathrm{~s}^{-1}$. The machine is capable of collecting on average of 1500 to $2000 \mathrm{~kg}$ of clean loose fruits in a day. It was found that the average time taken to collect an average of $3.4 \mathrm{~kg}$ loose fruits at one collecting point is 40 seconds. This figure was achieved at $37 \%$ of palms being harvested per hectare (140 palms ha- $\left.{ }^{-1}\right)$. Based on the trials, it was also found that the average debris content in the collected loose fruit is $7.5 \%$ Table 2 and Figure 7.

A time and motion study was conducted at 3 different plots ( 1 plot $=1$ ha). The scattered loose fruits were heaped first in one place or point by 1 worker. Another 2 workers ( 1 driver and 1 loose fruit collector), were then moved into the field for collecting the heaped loose fruits. Number of collecting points, time to collect loose fruits at one collecting point and time complete the tasks for 1 plot were taken and recorded. The collected loose fruits were then weighed. The debris collected together with the loose fruits were then manually removed and weighed.

With the proposed design, the machine is also well integrated with mainline transportation system i.e. the sterilizer cage system. 


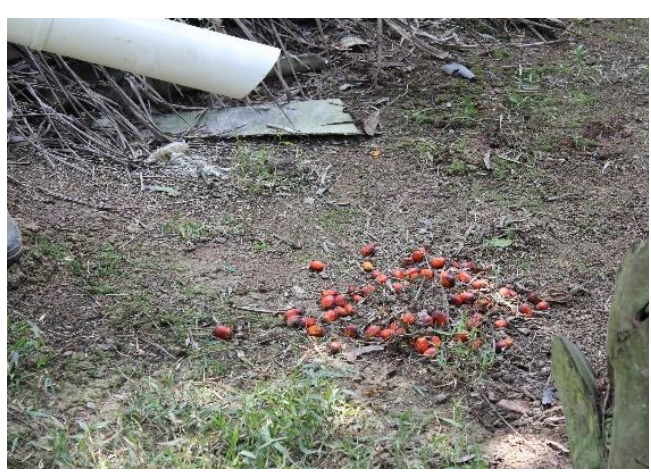

a- The loose fruits are gathered to a point

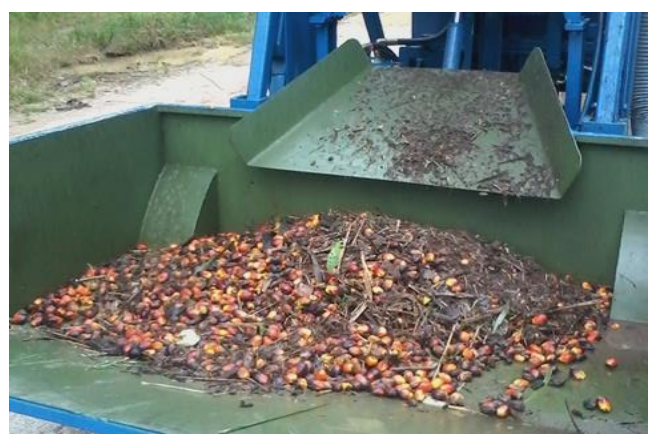

c- Once the fruit barrel is full it will unload to bin

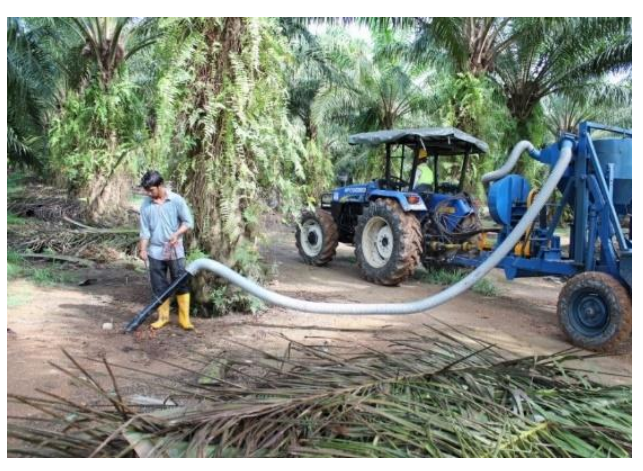

b- The machine moving towards the the loose fruits

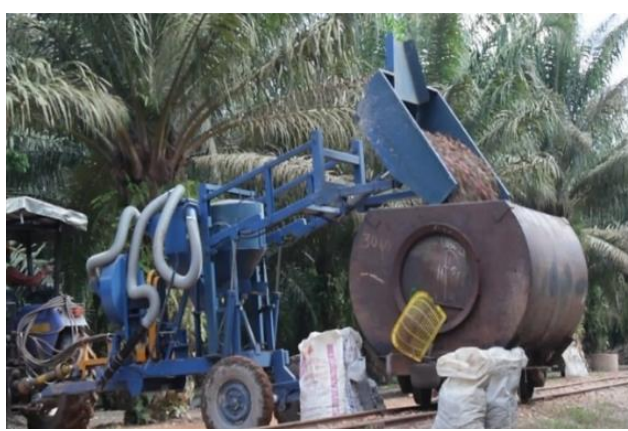

d- When the loose fruit bin reaching its capacity it will unload into cages or bin

Figure 7 Operational steps of collecting of loose fruits

TABLE 2. PERCENTAGE OF DEBRIS COLLECTED WITH LOOSE FRUITS BY USING THE MACHINE

$\begin{array}{cccc}\text { Replicates } & \begin{array}{c}\text { Weight of loose fruits } \\ \text { with debris, kg }\end{array} & \begin{array}{c}\text { Weight of debris being } \\ \text { removed, kg }\end{array} & \begin{array}{c}\text { Percentage of debris } \\ \text { from loose fruits, \% }\end{array} \\ 1 & 160 & 13 & 8.13 \\ 2 & 152 & 11 & 7.24 \\ 3 & 168 & 12 & 7.14 \\ \text { Average } & \mathbf{1 6 0} & \mathbf{1 2} & \mathbf{7 . 5}\end{array}$

Factors that affecting productivity of machine:

a) Field condition. Higher productivity in cleaner field.

b) Harvesting round and harvesting standard. The shorter harvesting round and the lower harvesting standard, the lower is the productivity as the machine has to travel further to collect loose fruits.

c) Palm height. The taller the palm, the lower the productivity as the machine has to cover bigger area due to the wider scattering of loose fruits.

d) Pre-raking. The use of machine is very effective in cases where the scattered fruits are being heaped in one place/point. 


\section{ECONOMIC ANALYSIS}

\section{Manufacturer point of view} business.

From the manufacturer point of view, the following economic analysis can be used as a reference if one to start the

\section{Assumption}

Material cost

Average production

Working day

Utilities and office

Labour cost

Operating cost per month (OPEX)

Capital expenditure (CAPEX)

\author{
: RM 15,000 machine - $^{-1}$ \\ : 10 units month ${ }^{-1}$ \\ : 26 days month $^{-1}$ \\ : RM 5,000 month $^{-1}$ \\ : RM 100 day $^{-1}$ (4 workers)
}

: RM 184,800

: RM 1,500,000

Hence, given the value of:

Internal rate of return (IRR) : $: 36 \%$

Payback period (PB) $\quad: 2.04$ years

Benefit cost ration $(\mathrm{B} / \mathrm{C}) \quad: 1.12: 1$

\section{User Perspective}

To calculate the operational coast, The American Society of Agricultural and Biological Engineers (ASABE) Standard was used in the calculation (details calculation as in Appendix I). The assumption and parameters used in the cost analysis are as follows:

Initial Cost

Operating hours (hr yr-1)

Total economic Life (hr)

Economic life (yr)

Salvage Value

Tax, shelter and insurance

Interest on investment

Fuel consumption (lh-1)

Fuel price (RM-1)

Lubricant cost

Repair and Maintenance Cost (RM/hr)

Labour requirement

Labour wages $\left(\mathrm{RM}\right.$ man $\left.^{-1} \mathrm{day}^{-1}\right)$

Total labour wages $\left(\mathrm{RM} \mathrm{hr}^{-1}\right)$
RM 60,000

3000

10000

3.33

$10 \%$ of the initial cost

$2 \%$ of the initial cost

$5 \%$ of the initial cost 3

2

$15 \%$ of the fuel cost

$5 \%$ of the initial cost

3 workers

36

13.5

Based on the above parameters, the cost to operate the machine is RM $23.40 \mathrm{hr}^{-1}$. With the loose fruits availability is $150 \mathrm{~kg}$ ha ${ }^{1}$, machine's output 2.07 tonne day ${ }^{-1}$ and manual collection cost of RM $31.05 \mathrm{hr}^{-1}$, thus given the operational cost per tonne as in Table 3. This comparison is based on the productivity of the machine that needs to be achieved by manual workforce practice. Thus, reflecting manual practice is more costly as compared to the machine for LF collecting activity.

TABLE 3. OPERATIONAL COST COMPARISON BETWEEN OIL PALM LOOSE FRUIT COLLECTING MACHINE AND MANUAL COLLECTION

\begin{tabular}{lcc}
\hline & Machine & Manual \\
\hline Labour requirement (man-day) & 3 & 7 \\
Labour wages $\left(\mathrm{RM} \mathrm{day}^{-1}\right)$ & 36 & 36 \\
Output per unit $\left(\mathrm{kg} \mathrm{day}^{-1}\right)$ & 2070 & 300 \\
Operational cost $\left(\mathrm{RM} \mathrm{tonne}^{-1}\right)$ & 90.43 & 120 \\
\hline
\end{tabular}




\section{CONCLUSION}

The development of this loose fruit collecting machine meets the criteria set in the objective. In general, the machine works well in areas that accessible to the conventional wheel type transporter hence improving the recovery of loose fruits.

This machine makes the collection of loose fruits more efficient. Loose fruits can now be sent to the mill with minimal contamination hence ensuring better quality and helping to reduce milling problems associated with the current method of collection.

\section{ACKNOWLEDGEMENT}

We would like to thank the Director-General specifically and management of MPOB generally for the support to conduct this research.

\section{REFERENCES}

[1] ABD RAHIM, S; MOHD RAMDHAN, K and MOHD SOLAH, D (2011). Chapter 17: Innovation and technologies for oil palm mechanization. Further Advances in Oil Palm Research (2000 2010) (Mohd Basri, W; Choo Y M and Chan, K W eds.). Vol. 1, MPOB, Bangi. p. 569-597.

[2] ABD RAHIM, S; MOHD RAMDHAN, K; MOHD SOLAH, D and Aminulrashid, M (2012). Oil palm loose fruits collecting machine (MK III). MPOB Information Series No. 592, palmolis.mpob.gov.my/ publication/TOT/TT-505.pdf.

[3] AHMAD, H; AHMAD ZAMRI, Y and MOHD SALIH, J (1995). Loose fruit collector. PORIM Information Series No.19. palmoilis.mpob.gov.my/publications/TOT/TT-19.pdf.

[4] BASIRON, Y (2007). Palm Oil Production through Sustainable Plantations. European Journal Lipid Science Technology, 109, 289-295.

[5] GAN, L. T., HO C.Y., LAM, K. S. and CHEW, J.S. (1995). Optimum harvesting standards to maximize labour productivity and oil recovery. In : Proc 1993 PORIM Int. Oil Palm Congress - Update and Vision, Kuala Lumpur, p 195-211.

[6] MOHD RAMDHAN, K and ABD RAHIM, S (2014). Field evaluation of oil palm mechanical harvesting machines for tall oil palms. Journal of Oil Palm Research Vol. 26 (2) June 2014: 125-132.

\section{DETAILS CALCULATION ON THE OPERATIONAL COST COMPARISON BETWEEN OIL PALM LOOSE FRUIT COLLECTING MACHINE AND MANUAL COLLECTION}

\section{$\underline{\text { ASSUMPTION }}$}

Initial Cost

60,000

Operating hours (hr/yr)

Total economic Life (hr)

Economic life (yr)

Salvage Value

Tax, shelter and insurance

$10 \%$ of the initial cost

Interest on investment

$2 \%$ of the initial cost

$5 \%$ of the initial cost

Fuel consumption $(1 / \mathrm{h})$

Fuel price (RM/l)

Lubricant cost

$15 \%$ of the fuel cost

Repair and Maintenance Cost (RM/hr)

\section{Machine's Cost (RM/Hour)}

Salvage Value (RM/hr)

Tax, shelter and insurance (RM/hr)

Interest on Investment (RM/hr)

Fuel cost (RM/hr)

Repair and Maintenance Cost (RM/hr)

Lubricant cost (RM/hr)

Labour requirement 
Total labour wages ( RM/hr)

13.5

Total (RM/hr)

23.40

LF production based on current practice at the site

Manual productivity (ha/man/day)

Productivity@15 bag of 20 kg/bag (kg/day)

Thus, LF availability (kg/ha)

Based on the field test validation:

Time to complete the tasks ( $\mathrm{min} / \mathrm{ha}$ )

or ave. effective field capacity (ha/hr)

Thus, equivalent to (ha/day)

$\underline{\text { Machine throughput (kg/day) }}$

$\underline{\text { Equivalent manual practice to achieve machine's productivity }}$

Labour requirement (man/day) 7

Labour wages (man-RM/day)

Total labour cost (RM/day) 248.4

or Total Labour cost (RM/hr) 31.05

\section{Comparison of the Operational Cost (RM/Tonne)}

To achieved the equivalent output of 2.07 tonne/day (or 0.26 tonne/hr), thus the operational cost of manual and machine are:

\begin{tabular}{lcc}
\hline & MACHINE & MANUAL PRACTICE \\
\cline { 2 - 3 } Operational cost (RM/tonne) & 90.43 & 120.00 \\
\hline
\end{tabular}

